\title{
Comment on "Venous and Arterial Thromboses: Two Sides of the Same Coin?"
}

\author{
Silvia Hoirisch-Clapauch, $\mathrm{MD}, \mathrm{PhD}^{1}$ \\ ${ }^{1}$ Hospital Federal dos Servidores do Estado, Rio de Janeiro, Brazil \\ Semin Thromb Hemost 2019;45:113-114.
}

I read with interest Lippi and Favaloro's paper discussing aspects of venous and arterial thromboses. ${ }^{1}$ I wonder whether anxiety-related hyperfibrinolysis and depressionrelated hypofibrinolysis could explain the difference between white and red arterial thrombi.

White thrombi, for example, are seen in about three-quarters of the patients with unstable angina, but not in patients with myocardial infarction. ${ }^{2}$ Unstable angina is associated with the rupture of the fibrous cap covering the atherosclerotic plaque, which often results from physical stress or anxiety, a physiological response to emotional stress. ${ }^{3}$ Three important processes related to stress-induced catecholamine release contribute to thrombi formation: vasoconstriction, coagulation abnormalities, and, paradoxical as it may seem, hyperfibrinolysis. Vasoconstriction not only favors plaque rupture by increasing shear forces on atherosclerotic plaques but also shifts fluid from the intravascular to the extravascular compartment, thus increasing viscosity. The coagulation abnormalities accompanying anxiety include increased levels of factor VIII, fibrinogen, and von Willebrand factor. ${ }^{4}$ Anxiety is also characterized by increased platelet aggregability, ${ }^{5}$ which accounts for the high platelet content of the white thrombus, and by acute release of tissue plasminogen activator (tPA) into the circulation. ${ }^{6}$ Resultant hyperfibrinolysis may render plaques vulnerable to rupture because matrix metalloproteinases (MMPs) such as MMP9 are activated by plasmin. MMP9, highly expressed in unstable coronary atherosclerotic plaques, degrades the extracellular matrix, weakening the plaque's fibrous cap ${ }^{3}$ and exposing plaque lipids and the subendothelial matrix to circulating blood.

Red thrombi are seen in all patients with myocardial infarction, but only in a minority of patients with unstable angina. These thrombi are usually formed in mildly or severely stenotic vessels, with superficial erosion or even without plaque rupture. While increased fibrinolytic activity seems to have a leading role in the pathogenesis of unstable angina, low fibrinolytic activity seems to be the common denominator to a variety of risk factors for myocardial infarction. For example, both cigarette smoking and inhalation of particulate air pollution impair endothelial
Address for correspondence Silvia Hoirisch-Clapauch, MD, PhD, Av. Atlantica 434-1101, CEP 22010-000, Rio de Janeiro, Brazil (e-mail: sclapauch@gmail.com).

release of tPA. ${ }^{8-10}$ In obesity, periodontal disorder, and other inflammatory conditions, high levels of tumor necrosis factor- $\alpha$ stimulate plasminogen activator inhibitor (PAI)-1 synthesis. ${ }^{8,11}$ Hyperhomocysteinemia, another risk factor for myocardial infarction, impairs tPA binding to its receptor, annexin A2, therefore inhibiting tPA activation of plasmin., 812

Two studies reinforce the hypothesis that comorbid anxiety and depression, not just anxiety, increases the risk of myocardial infarction. In one of these, the number of admissions related to myocardial infarction did not increase when the UK team played in the 2002 World Cup, the exception being when the United Kingdom lost to Argentina in a penalty shoot-out. ${ }^{13}$ A French study demonstrated that mortality related to myocardial infarction reduced when the French team won the World Cup in 1998. ${ }^{14}$

The links between depression and hypofibrinolysis include a high prevalence of cigarette smoking impairing endothelial release of TPA, and increased levels of PAI-1, due to different mechanisms. ${ }^{12,15,16}$ Depressive disorders, in general, are associated with increased levels of tumor necrosis factor- $\alpha$. In its turn, melancholic depression is accompanied by hypercortisolism, while atypical depression is accompanied by postprandial hyperinsulinemia. All three, tumor necrosis factor- $\alpha$, cortisol, and insulin, stimulate PAI- 1 gene expression. ${ }^{11}$

Importantly, men tend to deny depression. ${ }^{17}$ For patients at risk for myocardial infarction, it is suggested that antidepressants should be prescribed not to treat depression but to restore fibrinolytic activity.

Funding

No funding was provided for this article.

Conflict of Interest

The author reports no conflict of interest.

\section{References}

1 Lippi G, Favaloro EJ. Venous and arterial thromboses: two sides of the same coin? Semin Thromb Hemost 2017 (e-pub ahead of print). Doi: $10.1055 / \mathrm{s}-0037-1607202$ published online June 18, 2018
Issue Theme Editorial Compilation VI; Guest Editors: Emmanuel J. Favaloro, PhD, FFSc (RCPA), and Giuseppe Lippi, MD.
Copyright (c) 2019 by Thieme Medical Publishers, Inc., 333 Seventh Avenue, New York, NY 10001, USA. Tel: +1(212) 584-4662.
DOI https://doi.org/ 10.1055/s-0038-1657780. ISSN 0094-6176. 
2 Mizuno K, Satomura K, Miyamoto A, et al. Angioscopic evaluation of coronary-artery thrombi in acute coronary syndromes. N Engl J Med 1992;326(05):287-291

3 Stone PH. Triggering myocardial infarction. N Engl J Med 2004; 351(17):1716-1718

4 von Känel R, Mills PJ, Fainman C, Dimsdale JE. Effects of psychological stress and psychiatric disorders on blood coagulation and fibrinolysis: a biobehavioral pathway to coronary artery disease? Psychosom Med 2001;63(04):531-544

5 Larsson PT, Hjemdahl P, Olsson G, Egberg N, Hornstra G. Altered platelet function during mental stress and adrenaline infusion in humans: evidence for an increased aggregability in vivo as measured by filtragometry. Clin Sci (Lond) 1989;76(04):369-376

6 Wang Y, Jiang X, Hand AR, et al. Additional evidence that the sympathetic nervous system regulates the vessel wall release of tissue plasminogen activator. Blood Coagul Fibrinolysis 2002;13(06): 471-481

7 Chen F, Eriksson P, Hansson GK, et al. Expression of matrix metalloproteinase 9 and its regulators in the unstable coronary atherosclerotic plaque. Int J Mol Med 2005;15(01):57-65

8 Piepoli MF, Hoes AW, Agewall S, et al; Authors/Task Force Members. 2016 European guidelines on cardiovascular disease prevention in clinical practice: The Sixth Joint Task Force of the European Society of Cardiology and Other Societies on Cardiovascular Disease Prevention in Clinical Practice (constituted by representatives of 10 societies and by invited experts). Developed with the special contribution of the European Association for
Cardiovascular Prevention \& Rehabilitation (EACPR). Eur Heart J 2016;37(29):2315-2381

9 Newby DE, McLeod AL, Uren NG, et al. Impaired coronary tissue plasminogen activator release is associated with coronary atherosclerosis and cigarette smoking: direct link between endothelial dysfunction and atherothrombosis. Circulation 2001;103(15): 1936-1941

10 Mills NL, Törnqvist H, Robinson SD, et al. Air pollution and atherothrombosis. Inhal Toxicol 2007;19(Suppl 1):81-89

11 Vaughan DE. PAI-1 and atherothrombosis. J Thromb Haemost 2005;3(08):1879-1883

12 Luo M, Hajjar KA. Annexin A2 system in human biology: cell surface and beyond. Semin Thromb Hemost 2013;39(04):338-346

13 Carroll D, Ebrahim S, Tilling K, Macleod J, Smith GD. Admissions for myocardial infarction and World Cup football: database survey. BMJ 2002;325(7378):1439-1442

14 Berthier F, Boulay F. Lower myocardial infarction mortality in French men the day France won the 1998 World Cup of football. Heart 2003;89(05):555-556

15 Dowlati Y, Herrmann N, Swardfager W, et al. A meta-analysis of cytokines in major depression. Biol Psychiatry 2010;67(05):446-457

16 Kunugi H, Hori H, Ogawa S. Biochemical markers subtyping major depressive disorder. Psychiatry Clin Neurosci 2015;69(10):597-608

17 Rice SM, Aucote HM, Parker AG, Alvarez-Jimenez M, Filia KM, Amminger GP. Men's perceived barriers to help seeking for depression: longitudinal findings relative to symptom onset and duration. J Health Psychol 2017;22(05):529-536 